\title{
The association between metabolic syndrome and pressure ulcers among individuals living with spinal cord injury
}

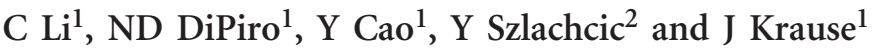

Objective: The objective of this study was to identify the relationship between metabolic syndrome (MetS) and pressure ulcers (PrU), after controlling for demographic and injury characteristics, socioeconomic factors, health behaviors and fatigue among participants with spinal cord injury (SCI).

Methods: This cross-sectional study recruited 350 participants with SCI from a hospital in the western region of the USA. Blood tests and physical examination were performed. Waist circumference, high-density cholesterol, triglycerides, blood pressure and fasting glucose were used to diagnose MetS according to Criteria for Clinical Diagnosis of Metabolic Syndrome defined by the American Heart Association. All other variables were self-reported. Three-stage multivariate logistic regression models were conducted to evaluate the effects of three sequential sets of predictors, including demographic/injury, socio-environmental/behavioral and health factors, basing the order of analysis on the Theoretical Risk and Prevention Model.

Results: The prevalence of PrU and MetS was $11.0 \%(n=36)$ and $35.3 \%(n=115)$, respectively. Ethnicity, smoking, alcohol consumption and MetS were statistically associated with PrU in the full model. Participants who were non-Hispanic (odds ratio $(\mathrm{OR})=10.30,95 \%$ confidence interval $(\mathrm{Cl}): 3.46-30.65)$, smokers $(\mathrm{OR}=2.69,95 \% \mathrm{Cl}: 1.00-7.27)$ and drank over 30 drinks per month $(\mathrm{OR}=5.26,95 \% \mathrm{Cl}: 1.24-22.26)$ had greater odds of having a PrU compared with those who were Hispanic, non-smokers and non-drinkers, respectively. We also observed a positive association between MetS and PrU (OR $\mathrm{Mets}_{\mathbf{M}}=3.71,95 \% \mathrm{Cl}$ : 1.45-9.52), even after controlling for all other factors.

Conclusion: Participants who had MetS had higher odds of PrU than those without MetS after adjusting for multiple covariates. Unhealthy behaviors such as smoking and excess drinking were positively associated with PrU.

Spinal Cord (2016) 54, 967-972; doi:10.1038/sc.2016.53; published online 19 April 2016

\section{INTRODUCTION}

Spinal cord injury (SCI) often results in significant physiologic and functional changes, predisposing individuals to a higher risk of both acute and chronic secondary health conditions. In particular, owing to motor and sensory impairments, mobility limitations and changes in skin composition, individuals with SCI are prone to developing pressure ulcers (PrU). A PrU is defined as an injury to the skin or an underlying tissue, commonly over a bony prominence, as a result of pressure and/or shear. ${ }^{1}$ Large cross-sectional studies of people with chronic SCI have found that $16-24 \%$ report having a PrU at a given time, ${ }^{2-6}$ and $32-48 \%$ report having a PrU in the past year. ${ }^{2-7}$ Despite considerable research focused on the identification of risk factors, prevention and treatment for $\operatorname{PrU},{ }^{8-14}$ at least one study suggested that the prevalence of PrUs has increased in recent years, ${ }^{15}$ and PrUs remain one of the most common and devastating sequelae after SCI.

Several sets of factors have been investigated in relation to PrU outcomes, all of which can be structured according to the Theoretical Risk and Prevention Model, with four levels of predictors: (i) demographic and injury level, (ii) socio-environmental and psychological, (iii) behavioral and (iv) health outcomes. ${ }^{16}$ Several biographic, injury and disability factors have been found to significantly increase the odds of a PrU. An early review suggested an increased risk of $\operatorname{PrU}$ with advancing age; ${ }^{17}$ however, the associations between age and $\operatorname{PrU}$ are inconsistent, and data from recent systematic reviews suggest that age is likely to be a multi-factorial PrU risk factor. ${ }^{10,13}$ There has been moderate to strong evidence that sex, age at injury and time since injury are significant PrU risk factors for individuals with chronic SCI. ${ }^{10}$ Several more recent cross-sectional studies have found that sex (male at greater risk of PrU), 5 race/ethnicity (American Indian and African American at greater risk of $\operatorname{PrU}),{ }^{4-6}$ injury severity ${ }^{4-6}$ and years post injury ${ }^{5-7}$ were significantly associated with self-reported $\operatorname{PrU}$ outcomes (current $\operatorname{PrU}$, at least one PrU in the past year and at least one PrU surgery).

Socio-environmental factors have been linked with PrU. According to the review by Gelis et al., ${ }^{10}$ there was a moderate level of evidence that education, marital status and employment status are protective or risk factors for PrU in chronic SCI. Other studies have identified income $^{5-7}$ and social support ${ }^{4}$ as socio-environmental factors associated with PrU outcomes. Few studies have assessed psychological factors in relation to $\operatorname{PrU}$, and there was insufficient evidence to suggest that they are risk factors. $3,7,18,19$

Numerous health behaviors and medical conditions have been associated with PrU. Cigarette smoking, ${ }^{7,10,17,20}$ using prescription medications $s^{2,7}$ and being underweight (a proxy measure for poor

${ }^{1}$ Medical University of South Carolina, Charleston, SC, USA and ${ }^{2}$ Rancho Los Amigos National Rehabilitation Center, Downey, CA, USA

Correspondence: Dr C Li, Department of Health Sciences and Research, Medical University of South Carolina, 77 President Street, Suite C101, MSC 700, Charleston, SC 29425, USA

E-mail: licha@musc.edu

Received 25 January 2016; revised 3 March 2016; accepted 15 March 2016; published online 19 April 2016 
nutrition $)^{2}$ are risk factors for PrU. Healthy lifestyle, diet, fitness and increased hours out of bed and days out of house have been identified as protective factors. ${ }^{2,3,7}$

There is moderate to strong evidence that medical factors including deep venous thrombosis, pneumonia or pulmonary conditions, lower limb fractures and autonomic dysreflexia are risk factors for PrUs. ${ }^{10}$ The evidence for cardiovascular disease as a risk factor for PrU was insufficient. ${ }^{10}$ Diabetes has been suggested as a factor associated with $\operatorname{PrU}$, but the findings were mixed, and the evidence was insufficient. ${ }^{10,13,17,20-22}$

The impact of metabolic syndrome (MetS) on PrU has yet to be explored. MetS is a cluster of conditions such as obesity, hypertension,

Table 1 Participant characteristics by pressure ulcer (PrU) status

\begin{tabular}{|c|c|c|c|c|}
\hline & PrU now & No PrU now & Total & P-value \\
\hline \multicolumn{5}{|c|}{ n (row \%) unless otherwise specified } \\
\hline \multicolumn{5}{|c|}{ Ethnicity } \\
\hline Hispanic & $13(36.1)$ & $191(65.9)$ & $204(62.6)$ & 0.0005 \\
\hline Non-Hispanic & $23(63.9)$ & $99(34.1)$ & $122(37.4)$ & \\
\hline \multicolumn{5}{|l|}{ Sex } \\
\hline Female & $4(11.1)$ & $48(16.5)$ & $52(15.9)$ & 0.4004 \\
\hline Male & $32(88.9)$ & $242(83.5)$ & $274(84.1)$ & \\
\hline Age at injury (mean \pm s.d.) & $26.8 \pm 11.8$ & $26.8 \pm 9.8$ & $26.8 \pm 10.0$ & 0.9997 \\
\hline \multicolumn{5}{|l|}{ Injury severity } \\
\hline Ambulatory & $3(8.3)$ & $42(14.5)$ & $45(13.8)$ & 0.3564 \\
\hline C14: non-ambulatory & $5(13.9)$ & $19(6.6)$ & $24(7.4)$ & \\
\hline C58: non-ambulatory & $7(19.4)$ & $55(19.0)$ & $62(19.0)$ & \\
\hline Others non-ambulatory & $21(58.3)$ & $174(60.0)$ & $195(59.8)$ & \\
\hline \multicolumn{5}{|l|}{ Education } \\
\hline Less than high school & $15(41.7)$ & 115 (39.7) & 130 (39.9) & 0.6281 \\
\hline High School & $17(47.2)$ & $140(48.3)$ & $157(48.2)$ & \\
\hline Bachelor & $1(2.8)$ & $21(7.2)$ & $22(6.8)$ & \\
\hline Above Bachelor & $3(8.3)$ & $14(4.8)$ & $17(5.2)$ & \\
\hline \multicolumn{5}{|l|}{ Income } \\
\hline$<\$ 25 \mathrm{~K}$ & $23(69.7)$ & $200(74.9)$ & $223(74.3)$ & 0.5549 \\
\hline$\$ 25-75 \mathrm{~K}$ & $9(27.3)$ & 53 (19.9) & $62(20.7)$ & \\
\hline$>\$ 75 \mathrm{~K}$ & $1(3.0)$ & $14(5.2)$ & $15(5.0)$ & \\
\hline \multicolumn{5}{|l|}{ Health insurance } \\
\hline No & $3(8.3)$ & $13(4.5)$ & $16(4.9)$ & 0.3131 \\
\hline Yes & $33(91.7)$ & $277(95.5)$ & $310(95.1)$ & \\
\hline \multicolumn{5}{|l|}{ Current smoking status } \\
\hline No & $23(63.9)$ & 227 (78.3) & $250(76.7)$ & 0.0542 \\
\hline Yes & $13(36.1)$ & $63(21.7)$ & $76(23.3)$ & \\
\hline \multicolumn{5}{|l|}{ Alcohol consumption } \\
\hline None at all & $17(47.2)$ & 137 (47.2) & $154(47.2)$ & 0.454 \\
\hline 1-30 drinks per month & $14(38.9)$ & $130(44.8)$ & $144(44.2)$ & \\
\hline$>30$ drinks per month & $5(13.9)$ & $23(7.9)$ & $28(8.6)$ & \\
\hline $\begin{array}{l}\text { Modified fatigue impact } \\
\text { score (mean } \pm \text { s.d.) }\end{array}$ & $7.3 \pm 5.8$ & $6.9 \pm 4.8$ & $7.0 \pm 4.9$ & 0.6231 \\
\hline \multicolumn{5}{|l|}{ Metabolic syndrome } \\
\hline No & $15(41.7)$ & $196(67.6)$ & 211 (64.7) & 0.0021 \\
\hline Yes & $21(58.3)$ & $94(32.4)$ & 115 (35.3) & \\
\hline
\end{tabular}

diabetes, elevated triglycerides and reduced high density lipoproteincholesterol (HDL-c), which increase heart disease and diabetes risk. ${ }^{23}$ There are several reasons to hypothesize that MetS may be associated with PrU: (i) obesity increases difficulties in turning and repositioning, which leads to ineffectively relieving pressure on skin and body tissue; $^{24}$ (ii) elevated triglycerides and reduced HDL-c contribute to plaque buildup and thicker blood, which leads to slower oxygen and nutrition transportation to the skin; ${ }^{25,26}$ (iii) hypertension is highly associated with diabetes, ${ }^{27}$ and elevated blood sugar is associated with nerve damage (neuropathy), capillaries and poor circulation, which can disturb normal blood flow; ${ }^{28}$ (iv) each component of MetS is correlated with each other, which may trigger a joint effect exaggerating PrU development beyond that of a single component alone.

The objective of the present study was to fill the knowledge gap by assessing the association between MetS and the odds of having a $\operatorname{PrU}$, while also examining the association of demographic and injury characteristics, socioeconomic and behavioral factors, and fatigue with $\operatorname{PrU}$. The sequence of inclusion of predictive factors follows that of the Theoretical Risk and Prevention Model. ${ }^{16}$

\section{METHODS}

\section{Study design and population}

This cross-sectional study built upon a 17 -year cohort study conducted in a hospital in the western region of the USA (a subset of participants participated 17 years earlier). ${ }^{29}$ The inclusion criteria were (i) 18 years or older, (ii) traumatic SCI with residual deficits (that is, not a complete recovery) and (iii) over 1 year since SCI onset. Institutional review board approval was obtained before initiating data collection. Data were collected from August 2011 to February 2014. From a total of 350 participants, 13 did not provide valid self-report $\operatorname{PrU}$ information and 11 did not complete all the clinical assessments, which reduced the final sample to 326. Participant characteristics are summarized in Table 1.

\section{Data collection}

Informed consent was obtained prior to data collection. Those agreeing to participate were sent a self-report questionnaire and were scheduled for clinical assessment. Participants either returned the questionnaire by mail or completed it at the time of their clinical appointment. Participants received $\$ 150$ as remuneration for completing both parts of the assessment and to cover travel expenses to get to the clinic.

\section{Measurement of variables}

Participants completed a self-report assessment that encompassed multiple areas of life, including measurement of study covariates. These included the following demographic and injury characteristics: ethnicity (Hispanic and nonHispanic), sex (female and male), age at injury, years since injury and injury severity. A combination of ambulatory status and neurologic level was used to measure injury severity, forming four categories, with all ambulatory cases classified together (regardless of injury level) and the non-ambulatory participants broken down as follows: C1-C4, C5-C8 and non-cervical. For the socioeconomic variables, education was broken down into four groups based on the highest level achieved (less than high school, high school, bachelor and above bachelor), whereas income was broken down into three categories $(<\$ 25 \mathrm{~K}, \$ 25 \mathrm{~K}-75 \mathrm{~K}$ and $>\$ 75 \mathrm{~K})$ and health insurance was dichotomized (yes/no). Behavioral factors included current smoking status (yes/no), and alcohol consumption was broken down into three groups (none at all, 1-30 drinks per month and $>30$ drinks per month). Fatigue was measured by the Modified Fatigue Impact Scale, ${ }^{30,31}$ which is a 5-item instrument to capture the influence of fatigue on daily life.

The main outcome (PrU) of this study was measured by a self-reported question, which was 'Do you currently have an open pressure/skin ulcer?' Responses to this question were dichotomized as yes or no. 


\section{Measurement of MetS}

Fasting blood sample was obtained under metabolic stability conditions ( $8 \mathrm{~h}$ of fasting) by using standard phlebotomy protocol and analyzed in the laboratory of the same hospital during the appointment. Physical examination was also conducted to measure waist circumference and systolic and diastolic blood pressure. Waist circumference was measured by a measuring tape in a horizontal plane around the narrowest point between the ribs and the iliac crest. Systolic and diastolic blood pressures were measured by the standard Hypertension Detection and Follow-up Program protocol. ${ }^{32}$ Three supine blood pressure readings were taken, and mean systolic and diastolic blood pressures were calculated from the second and third readings.

MetS was diagnosed according to Criteria for Clinical Diagnosis of Metabolic Syndrome (CCDMS) defined by the American Heart Association. ${ }^{33}$ Five measures in the CCDMS were used to define MetS, which were elevated waist circumference $(\geqslant 102 \mathrm{~cm}$ ( $\geqslant 40$ inches) in men and $\geqslant 88 \mathrm{~cm}$ ( $\geqslant 35$ inches) in women), elevated triglycerides $\left(\geqslant 150 \mathrm{mg} \mathrm{dl}^{-1}\left(1.7 \mathrm{mmoll}^{-1}\right)\right.$ or on drug treatment for elevated triglycerides), reduced HDL-c $\left(<40 \mathrm{mg} \mathrm{dl}^{-1}\right.$ $\left(1.03 \mathrm{mmoll}^{-1}\right)$ in men and $<50 \mathrm{mg} \mathrm{dl}^{-1}\left(1.3 \mathrm{mmoll}^{-1}\right)$ in women or on drug treatment for reduced HDL-c), elevated blood pressure $(\geqslant 130 \mathrm{~mm} \mathrm{Hg}$ systolic blood pressure or $\geqslant 85 \mathrm{~mm} \mathrm{Hg}$ diastolic blood pressure or on antihypertensive drug treatment in a patient with a history of hypertension) and elevated fasting glucose $\left(\geqslant 100 \mathrm{mg} \mathrm{dl}^{-1}\right.$ or on drug treatment for elevated glucose). Any three of five measures constituted diagnosis of MetS.

\section{Data analysis}

Continuous variables are demonstrated as the mean and standard deviation and tested by a $t$-test. Categorical variables are shown as the frequency and percentage and tested by the chi-square test.

Three-stage multivariate logistic regression models were developed to evaluate the association between MetS and PrU. Consistent with the Theoretical Risk and Prevention Model, we included demographic and injury variables in the first model (ethnicity, sex, age at injury, years since injury, injury severity), followed by socio-environmental and behavioral variables in the second model (education, income, health insurance, current smoking status and alcohol consumption), and health variables in the third model (Modified Fatigue Impact score and MetS).

SAS (Version 9.4, SAS institute Inc, Cary, NC, USA) was used to conduct all statistical analyses. The standard of significance was set at $P<0.05$.

\section{Statement of ethics}

We certify that all applicable institutional and governmental regulations concerning the ethical use of human volunteer were followed during the course of this research.

Table 2 Metabolic syndrome and its indicators

\begin{tabular}{lrrr}
\hline & Yes: n (\%) & No: n (\%) & Total \\
\hline Elevated blood pressure $^{\mathrm{a}}$ & $106(32.5)$ & $220(67.5)$ & 326 \\
Elevated triglycerides $^{\mathrm{b}}$ & $116(35.6)$ & $210(64.4)$ & 326 \\
Reduced HDL-c $^{c}$ & $158(48.5)$ & $168(51.5)$ & 326 \\
Elevated waist circumference $^{\mathrm{d}}$ & $212(65.0)$ & $114(35.0)$ & 326 \\
Elevated fasting glucose $^{\mathrm{e}}$ & $69(21.2)$ & $257(78.8)$ & 326 \\
Metabolic syndrome & $115(35.3)$ & $211(64.7)$ & 326
\end{tabular}

Abbreviation: HDL-c, high density lipoprotein-cholesterol.

Criteria for clinical diagnosis of metabolic syndrome:

aElevated blood pressure: $\geqslant 130 \mathrm{~mm} \mathrm{Hg}$ systolic blood pressure or $\geqslant 85 \mathrm{~mm} \mathrm{Hg}$ diastolic blood pressure or on antihypertensive drug treatment in a patient with a history of hypertension. belevated triglycerides: $\geqslant 150 \mathrm{mg} \mathrm{dl}^{-1}\left(1.7 \mathrm{mmol}^{-1}\right)$ or on triglycerides.

'Reduced HDL-c: $<40 \mathrm{mg} \mathrm{dl}^{-1}\left(1.03 \mathrm{mmoll}^{-1}\right)$ in men and $<50 \mathrm{mg} \mathrm{dl}^{-1}\left(1.3 \mathrm{mmoll}^{-1}\right)$ in ${ }^{C}$ Reduced $\mathrm{HDL}-\mathrm{c}:<40 \mathrm{mg} \mathrm{dl}$
women or on drug treatment for reduced $\mathrm{HDL}-\mathrm{C}$.

dElevated waist circumference: $\geqslant 102 \mathrm{~cm}(\geqslant 40$ inches) in men and $\geqslant 88 \mathrm{~cm}$ ( $\geqslant 35$ inches) in women.

eElevated fasting glucose: $\geqslant 100 \mathrm{mg} \mathrm{dl}^{-1}$ or on drug treatment for elevated glucose.

\section{RESULTS}

Descriptive analysis

There were $11.0 \% \quad(n=36)$ of participants who had $\operatorname{PrU}$ now (Table 1). Among them, 63.9\% $(n=23)$ were non-Hispanics and $36.1 \%(n=13)$ were Hispanic. In comparison, among people who did not have a $\operatorname{PrU}$ now, $34.1 \%(n=99)$ were non-Hispanic and $65.9 \%$ $(n=191)$ were Hispanic. The participants were similar with respect to sex, age at injury, education, income, insurance and Modified Fatigue Impact score among those with and without $\operatorname{PrU}$ now. The percentages of smoking, drinking $>30$ drinks per month and having MetS were higher among people who had PrU now than those who did not.

\section{MetS and chronic health conditions}

On the basis of the CCDMS, 35.3\% $(n=115)$ were diagnosed with MetS (Table 2). Of the 326 participants, 32.5\% $(n=106)$ had elevated blood pressure, $35.6 \%(n=116)$ had increased triglycerides, $48.5 \%$ $(n=158)$ had reduced HDL-c, 65.0\% $(n=212)$ had elevated waist circumference and 21.2\% $(n=69)$ had elevated fasting glucose.

\section{Logistic regression}

In the first model, ethnicity was significantly associated with PrU. Compared with Hispanics, non-Hispanics (odds ratio $(\mathrm{OR})=4.05$, 95\% confidence interval (CI): 1.86-8.80) had higher odds of having PrU now. Sex, age at injury and injury severity were not significantly associated with PrU. In model 2, ethnicity was the only significant factor, as none of the newly added socio-environmental or behavioral predictors was statistically significant.

The fit of the third and final model was improved after including MetS and Modified Fatigue Impact score (significant likelihood ratio test, Table 3). Besides the significant association between ethnicity and $\operatorname{PrU}\left(\mathrm{OR}_{\text {non-Hispanic }}=10.30\right.$, 95\% CI: 3.46-30.65), we also observed that participants who had MetS $(\mathrm{OR}=3.71,95 \% \mathrm{CI}$ : $1.45-9.52)$ had significantly higher odds of having PrU. Interestingly, those who smoked $(\mathrm{OR}=2.69,95 \% \mathrm{CI}: 1.00-7.27)$ or drank over 30 drinks per month $(\mathrm{OR}=5.26,95 \% \mathrm{CI}$ : $1.24-22.26)$ also had a greater risk of PrU, only after inclusion of MetS and fatigue (Table 3).

\section{DISCUSSION}

This study adds to our body of knowledge on factors associated with PrUs after SCI, with several unique contributions including as follows: (i) to our knowledge, ours is the first study to evaluate the relationship between MetS and PrU after SCI, (ii) inclusion of a large portion of Hispanic participants, (iii) inclusion of both self-report and clinical data and (iv) evaluation of multiple factors from the Theoretical Risk and Prevention Model that include socioeconomic, behavioral and health factors, which allow us to control for multiple covariates. Our key findings are that non-Hispanics and those who reported unhealthy behaviors (smoking and excess drinking) were more likely to report a current PrU. We also found that participants who had MetS had higher odds of $\operatorname{PrU}$ than those without MetS after multivariate adjustment.

There are several plausible explanations for the relationship between MetS and PrU. Each component of MetS has its own biological potentials to impact pressure on the $\operatorname{skin}^{24}$ and/or normal blood flow that transports oxygen and nutrition to the skin. ${ }^{25-28}$ It is very likely that MetS can contribute to the development of $\operatorname{PrU}$, as well as slow down the recovery from PrU. However, it is also possible that a history of PrUs elevates the risk for MetS due to inactivity or other consequences of PrUs. 
Table 3 Multi-stage logistic regression models

\begin{tabular}{|c|c|c|c|c|c|c|}
\hline & \multicolumn{2}{|c|}{ Model 1} & \multicolumn{2}{|c|}{ Model 2} & \multicolumn{2}{|c|}{ Model 3} \\
\hline & OR $(95 \% \mathrm{Cl})$ & $\begin{array}{l}\text { P-value } \\
0.0004\end{array}$ & OR $(95 \% \mathrm{Cl})$ & P-value & OR $(95 \% \mathrm{Cl})$ & P-value \\
\hline Non-Hispanic & $4.05(1.86-8.80)$ & & $5.37(2.10-13.73)$ & & $10.30(3.46-30.65)$ & \\
\hline $\begin{array}{l}\text { Gender } \\
\qquad(\text { ref }=\text { Male })\end{array}$ & & 0.2548 & & 0.4456 & & 0.2244 \\
\hline Age at injury & $0.97(0.93-1.02)$ & 0.2683 & $0.97(0.92-1.02)$ & 0.2634 & $0.96(0.91-1.02)$ & 0.1718 \\
\hline Years since injury & $0.99(0.95-1.03)$ & 0.5081 & $0.98(0.94-1.03)$ & 0.3883 & $0.97(0.92-1.02)$ & 0.1991 \\
\hline $\begin{array}{l}\text { Injury severity } \\
\qquad(\text { ref }=\text { Ambulatory })\end{array}$ & & 0.5374 & & 0.1850 & & 0.1846 \\
\hline C14: Non-ambulatory & $2.85(0.58-14.08)$ & & $3.38(0.59-19.33)$ & & $6.43(0.74-55.78)$ & \\
\hline C58: Non-ambulatory & $1.46(0.33-6.42)$ & & $1.55(0.30-7.87)$ & & $3.22(0.39-26.63)$ & \\
\hline Bachelor & - & - & $0.36(0.04-3.34)$ & & $0.27(0.03-2.82)$ & \\
\hline Less than High School & - & - & $0.99(0.41-2.41)$ & & $0.98(0.37-2.55)$ & \\
\hline Income & & & & 0.1786 & & 0.0933 \\
\hline$(\mathrm{ref}=<\$ 25 \mathrm{k})$ & - & - & & & & \\
\hline$\$ 25-75 \mathrm{~K}$ & - & - & $1.99(0.74-5.37)$ & & $2.63(0.88-7.85)$ & \\
\hline$>\$ 75 k$ & - & - & $0.29(0.03-3.44)$ & & $0.26(0.02-3.44)$ & \\
\hline Insurance & & - & & 0.2803 & & 0.1559 \\
\hline$($ ref $=$ Yes $)$ & - & - & & & & \\
\hline No & - & - & $0.38(0.07-2.19)$ & & $0.25(0.04-1.71)$ & \\
\hline Current smoking status & & & & 0.0932 & & 0.0506 \\
\hline$(\mathrm{ref}=\mathrm{No})$ & - & - & & & & \\
\hline Yes & - & - & - & - & $3.71(1.45-9.52)$ & \\
\hline$-2 \log L$ & 198.2 & & 169.3 & & 146.1 & \\
\hline
\end{tabular}

Abbreviations: $\mathrm{Cl}$, confidence interval; $\mathrm{OR}$, odds ratio.

An important finding was that none of the components of MetS (obesity, fasting glucose, HDL, triglycerides, systolic and diastolic blood pressure) was significantly related to current PrU. Therefore, no single element of MetS was sufficient to be significantly associated with PrU development, but the combination of these components of MetS was associated with the probability of a PrU. This may be through triggering the development or delaying the resolution of a $\operatorname{PrU}$, or conversely, the effects of the PrU on the development of MetS. The findings overall are with the concept of allostatic load, a biologic-based theory of stress, where only the combination or number of indicators is significant (not individual components). ${ }^{34}$

Blood pressure among people with SCI is more complicated than that of in the general population owing to orthostatic hypotension and autonomic dysreflexia. In regard to orthostatic hypotension, the diagnosis criteria of American Heart Association (AHA) (early stage of hypertension) are higher and more restrictive. In this study, we identified participants having MetS with higher blood pressure using American Heart Association (AHA) standards and found an insignificant association between hypertension and $\operatorname{PrU}$, which indicates that high blood pressure by itself may not be sufficient to have an impact on PrU. Therefore, we found that MetS, as a cluster of chronic health conditions, and hypertension presented differently among people with SCI.

We found that Hispanics had lower odds of having PrU than non-Hispanics, which is consistent with previous work by Saladin et al. ${ }^{4}$ that found race-ethnicity to be a risk factor for current $\mathrm{PrU}$ and higher prevalence of PrU among American Indians and African Americans compared with Hispanics, which is another scenario of 'Hispanic Paradox. ${ }^{35}$ However, several other studies reported contradictive results. ${ }^{3,21,36,37}$ As septicemia is one of the primary causes of mortality ${ }^{38}$ and septicemia has been reported to be associated with $\operatorname{PrU},{ }^{39,40}$ the lower prevalence of $\operatorname{PrU}$ may lead to a lower risk of mortality among Hispanics with SCI.

Smoking has been identified as a risk factor for PrU development by numerous studies, ${ }^{7,10,17,20}$ at least partially owing to nicotine possibly impairing the endothelial vasorelaxation function and leading to 
vasoconstriction in the vascular system, which has a negative impact on the healing progress of PrU. ${ }^{41-44}$ Our study also supported this relationship that current smokers had greater odds of having PrU than non-smokers. Although the influence of alcohol consumption on $\mathrm{PrU}$ is still controversial, we found evidence that excessive drinking is associated with $\operatorname{PrU}$. Meanwhile, most previous studies ${ }^{7,20}$ reported non-significant association between alcohol consumption and PrU. One possible explanation could be that previous studies used binge drinking as the indicator of alcohol consumption, and we used average number of drinks in a month as a proxy for alcohol consumption.

Fatigue is common and caused by multiple risk factors among individuals with SCI. ${ }^{45}$ Fatigue is typically presented as muscle fatigue and decreased endurance (physical construct), ${ }^{46,47}$ which further leads to less frequent repositioning to avoid stress on the skin. Each component of MetS has the potential to exacerbate fatigue that may increase the possibility of developing PrU. However, in this study, we studied fatigue as a potential confounder and did not find a significant association between fatigue and $\operatorname{PrU}$.

\section{Limitations}

There are several noteworthy limitations. First, this is a cross-sectional study that does not allow us to draw any causal conclusions that MetS causes PrU or PrU causes MetS. Second, the study participants were recruited from one hospital, which may affect the generalizability of our findings, although this would apply more to prevalence rates, rather than covariates. Third, although substantial for a clinical study, the size of the participant sample is still relatively small $(n=350)$ in terms of limiting the power in multivariate analyses.

\section{Future research}

As MetS is a chronic health condition and PrU can occur multiple times after SCI, prospective cohort studies are needed to assess the longitudinal association. We collected and analyzed longitudinal data on MetS with 150 of the participants (reported elsewhere), ${ }^{48}$ but there were no longitudinal data on PrUs. Research should also focus on the impact of MetS on previous PrU, severity of PrU and course of development, including progression. It may very well be that MetS affects the time of recovery, as opposed to the onset of a PrU. Moreover, additional studies are needed to confirm the association between current PrU and MetS in different SCI populations or those with differing characteristics.

\section{CONCLUSION}

PrU and MetS were observed in $11.0 \%$ and $35.3 \%$, respectively, of our sample. Participants who had MetS had greater odds of having current PrU than those without MetS. Being non-Hispanic and having unhealthy behaviors such as smoking and excess drinking were positively associated with current PrU.

\section{DATA ARCHIVING}

There were no data to deposit.

\section{CONFLICT OF INTEREST}

The authors declare no conflict of interest.

\section{ACKNOWLEDGEMENTS}

The contents of this presentation were developed under grants from the US Department of Health and Human Services Administration for Community Living, NIDILRR grant numbers 90RT5003 and 90DP0004. However, those contents do not necessarily represent the policy of the Department of Health and Human Services, and you should not assume endorsement by the Federal Government.

1 Black J, Baharestani M, Cuddigan J, Dorner B, Edsberg L, Langemo D et al. National Pressure Ulcer Advisory Panel's updated pressure ulcer staging system. Dermatol Nurs 2007; 19: 343-349.

2 Krause JS, Vines CL, Farley TL, Sniezek J, Coker J. An exploratory study of pressure ulcers after spinal cord injury: relationship to protective behaviors and risk factors. Arch Phys Med Rehabil 2001; 82: 107-113.

3 Krause JS, Broderick L. Patterns of recurrent pressure ulcers after spinal cord injury: Identification of risk and protective factors 5 or more years after onset. Arch Phys Med Rehabil 2004: 85: 1257-1264.

4 Saladin LS, Krause JS, Adkins RH. Pressure ulcer prevalence and barriers to treatment after spinal cord injury: comparisons of 4 groups based on race-ethnicity. NeuroRehabil 2009; 24: 57-66.

5 Saunders LL, Krause JS, Peters BA, Reed KS. The relationship of pressure ulcers, race, and socioeconomic conditions after spinal cord injury. J Spinal Cord Med 2010; 33: 387-395.

6 Saunders LL, Krause JS, Acuna J. Association of race, socioeconomic status, and health care access with pressure ulcers after spinal cord injury. Arch Phys Med Rehabil 2012; 93: 972-977.

7 Saunders LL, Krause JS. Personality and behavioral predictors of pressure ulcer history. Top Spinal Cord Inj Rehabil 2010; 16: 61-71.

8 DeJong G, Hsieh CH, Brown P, Smout RJ, Horn SD, Ballard P et al. Factors associated with pressure ulcer risk in spinal cord injury rehabilitation. Am J Phys Med Rehabil 2014; 93: 971-986.

9 Gelis A, Dupeyron A, Legros P, Benaim C, Pelissier J, Fattal C. Pressure ulcer risk factors in persons with SCI: part I: acute and rehabilitation stages. Spinal Cord 2009; 47: 99-107.

10 Gelis A, Dupeyron A, Legros P, Benaim C, Pelissier J, Fattal C. Pressure ulcer risk factors in persons with spinal cord injury: part 2: the chronic stage. Spinal Cord 2009; 47: 651-661.

11 DiVita MA, Granger CV, Goldstein R, Niewczyk P, Freudenheim JL. Risk factors for development of new or worsened pressure ulcers among patients in inpatient rehabilitation facilities in the United States: data from the Uniform Data System for Medical Rehabilitation. PMR 2015; 7: 599-612.

12 Regan M, Teasell R, Wolfe D, Keast D, Mortenson W, Aubut J. A systematic review of therapeutic interventions for pressure ulcers after spinal cord injury. American Congress of Rehabilitation Medicine 2009; 90: 213-231.

13 Marin J, Nixon J, Gorecki C. A systematic review of risk factors for the development and recurrence of pressure ulcers in people with spinal cord injuries. Spinal Cord 2013; 51: 522-527.

14 Groah SL, Schladen M, Pineda CG, Hsieh CH. Prevention of pressure ulcers among people with spinal cord injury: a systematic review. PMR 2015; 7: 613-636.

15 Chen Y, Devivo MJ, Jackson AB. Pressure ulcer prevalence in people with spinal cord injury: age-period-duration effects. Arch Phys Med Rehabil 2005; 86: 1208-1213.

16 Krause JS, Saunders LL, DiPiro ND, Reed KS. Theoretical risk and prevention model for secondary health conditions and mortality after SCl: 15 years of research. Top Spinal Cord Inj Rehabil 2013; 19: 15-24.

17 Byrne DW, Salzberg CA. Major risk factors for pressure ulcers in the spinal cord disabled: A literature review. Spinal Cord 1996; 34: 255-263.

18 Correa GI, Fuentes M, Gonzalez X, Cumsille F, Pineros JL, Finkelstein J. Predictive factors for pressure ulcers in the ambulatory stage of spinal cord injury patients. Spinal Cord 2006; 44: 734-739.

19 Elliott TR, Bush BA, Chen Y. Social problem-solving abilities predict pressure sore occurrence in the first 3 years of spinal cord injury. Rehabil Psychol 2006; 51: 69-77.

20 Smith BM, Guihan M, LaVela SL, Garber SL. Factors predicting pressure ulcers in veterans with spinal cord injuries. Am J Phys Med Rehabil 2008; 87: 750-757.

21 Garber SL, Rintala DH, Hart KA, Fuhrer MJ. Pressure ulcer risk in spinal cord injury: Predictors of ulcer status over 3 years. Arch Phys Med Rehabil 2000; 81. 465-471.

22 Rabadi $\mathrm{MH}$, Vincent AS. Do vascular risk factors contribute to the prevalence of pressure ulcer in veterans with spinal cord injury? J Spinal Cord Med 2011; 34: 46-51.

23 Grundy SM, Brewer HB Jr, Cleeman JI, Smith SC Jr, Lenfant C. American Heart Association; National Heart, Lung, and Blood Institute Definition of metabolic syndrome: Report of the National Heart, Lung, and Blood Institute/American Heart Association conference on scientific issues related to definition. Circulation 2004; 109 433-438.

24 Gardner LA, Pagano M. Skin integrity, immobility, and pressure ulcers in class III obese patients. Pennsylvania Patient Safety Advisory 2013; 10: 50-54.

25 Genest J. Lipoprotein disorders and cardiovascular risk. Inherit Met Dis 2003; 26: 267-287.

26 Rosenson RS. Low high-density lipoprotein cholesterol disorders and cardiovascular risk: contribution of associated low-density lipoprotein subclass abnormalities. Cur Opin Cardiol 2005; 20: 313-317.

27 Cheung BM, Li C. Diabetes and hypertension: is there a common metabolic pathway? Curr Atheroscler Rep 2012; 14: 160-166.

28 Diseases NloDaDaK. Diabetic Neuropathies: The Nerve Damage of Diabetes [cited 2015 11/10]. Available from: http://www.niddk.nih.gov/health-information/health-topics/ Diabetes/diabetic-neuropathies-nerve-damage-diabetes/Pages/diabetic-neuropathiesnerve-damage.aspx. accessed on 1 March 2016. 
29 Adkins RH, Szlachcic Y, Govindarajan S. Metabolic syndrome and spinal cord injury: A 17-year longitudinal study. Top Spinal Cord Inj Rehabil 2010; 16: 40-52.

30 Fisk JD, Ritvo PG, Ross L, Haase DA, Marrie TJ, Schlech WF. Measuring the functional impact of fatigue: initial validation of the fatigue impact scale. Clin Infect Dis 1994; 19: S79-S83.

31 Multiple Sclerosis Council for Clinical Practice Guidelines. Fatigue and multiple sclerosis: Evidence-based management of strategies for fatigue in multiple sclerosis. Paralyzed Veterans of America: Washington, DC, 1998.

32 Hypertension Detection and Follow-up Program Cooperative Group. Variability of blood pressure and results of screening in the hypertension detection and follow-up program. J Chron Dis 1978; 31: 651-667.

33 Grundy SM, Cleeman JI, Daniels SR, Donato KA, Eckel RH, Franklin BA et al. Diagnosis and management of the metabolic syndrome: an American Heart Association/National Heart, Lung, and Blood Institute scientific statement: Executive Summary. Crit Pathw Cardiol 2005; 4: 198-203.

34 Krause JS, DiPiro ND, Saunders LL, Newman SD, Banik NL, Park S. Allostatic load and spinal cord injury: review of existing research and preliminary data. Top Spinal Cord Inj Rehabil 2014; 20: 137-146.

35 Valles SA. The challenges of choosing and explaining a phenomenon in epidemiological research on the "Hispanic Paradox". Theor Med Bioeth (e-pub ahead of print 11 January 2016; doi:10.1007/s11017-015-9349-1).

36 Fuhrer MJ, Garber SL, Rintala DH, Clearman R, Hart KA. Pressure ulcers in communityresident persons with spinal cord injury: prevalence and risk factors. Arch Phys Med Rehabil 1993; 74: 1172-1177.

37 Krause JS. Skin sores after spinal cord injury: Relationship to life adjustment. Spinal Cord 1998; 36: 51-56.

38 Center NSCIS. Annual Statistical Report. Complete Public Version University of Alabama at Birmingham, 2014 https://www.nscisc.uab.edu/reports.aspx.
39 Thietje R, Pouw MH, Schulz AP, Kienast B, Hirschfeld S. Mortality in patients with traumatic spinal cord injury: descriptive analysis of 62 deceased subjects. J Spinal Cord Med 2011; 34: 482-487.

40 Soden RJ, Walsh J, Middleton JW, Craven ML, Rutkowski SB, Yeo JD. Causes of death after spinal cord injury. Spinal Cord 2000; 38: 604-610.

41 Noble M, Voegeli D, Clough GF. A comparison of cutaneous vascular responses to transient pressure loading in smokers and nonsmokers. J Rehabil Res Dev 2003; 40: 283-288.

42 ljzerman RG, Serne EH, van Weissenbruch MM, de Jongh RT, Stehouwer CD. Cigarette smoking is associated with an acute impairment of microvascular function in humans. Clin Sci 2003; 104: 247-252.

43 Dalla Vecchia L, Palombo C, Ciardetti M, Porta A, Milani O, Kozakova M et al. Contrasting effects of acute and chronic cigarette smoking on skin microcirculation in young healthy subjects. J Hypertens 2004; 22: 129-135.

44 Black CE, Huang N, Neligan PC, Levine RH, Lipa JE, Lintlop S et al. Effect of nicotine on vasoconstrictor and vasodilator responses in human skin vasculature. Am J Physiol Regul Integr Comp Physiol 2001; 281: R1097-R1104.

45 McColl MA, Arnold R, Charlifue S, Glass C, Savic G, Frankel H. Aging, spinal cord injury, and quality of life: structural relationships. Arch Phys Med Rehabil 2003; 84: 1137-1144.

46 Shields RK. Muscular, skeletal, and neural adaptations following spinal cord injury. J Orthop Sports Phys Ther 2002; 32: 65-74.

47 Gordon T. Fatigue in adapted systems. Overuse and underuse paradigms. Adv Exp Med Biol 1995; 384: 429-456.

48 Szlachcic Y, Adkins RH, Govindarajan S, Cao Y, Krause JS. Cardimetabolic changes and disparities among persons with spinal cord injury: a 17-year cohort study. Top Spinal Cord Inj Rehabil 2014; 20: 96-104. 